\title{
Managing Wireless Networks in the Healthcare Sector: Emerging Experiences of Cultural Impacts
}

\author{
Wenshin Chen ${ }^{1}$ and David Bennett ${ }^{2}$ \\ ${ }^{1}$ Abu Dhabi University, Abu Dhabi, UAE \\ ${ }^{2}$ Aston University, Birmingham, UK
}

\begin{abstract}
The existing body of knowledge has generally supported that organizational culture plays a significant role in shaping group identity, work pattern, communication schemes, and interpersonal relations; all of these cultural elements are important organizational factors that shape workplaces and operational routines. In the context of emerging information technology, it has also been suggested that organizational culture could affect IT implementation and management. However, little is known about how emerging information technology shapes organizational culture, which in turn helps reshape the organization as a whole. The purpose of this paper is thus to build empirical understanding of how IT in general and emerging wireless networks in particular reshapes organizational culture. Case studies conducted in two hospitals situated in southwest U.S.A. illustrated that the implementation of wireless networks indeed helped shape and/or reshape organizational culture in the healthcare sector and in turn enhance healthcare organizations' competitiveness in the marketplace. For IT managers and practitioners in healthcare institutions, effective strategy to plan and manage emerging ITs such as wireless networks will thus have long-term implications on cultivating organizational culture that could eventually reshape workplace and competitiveness.
\end{abstract}

Keywords: Healthcare, culture, wireless network, case study

\section{Research Background}

Wireless networks and mobile technology have been developed so fast in recent years that even amazon.com founder and CEO, Jeff Bezos, predicted that most e-commerce will be conducted on mobile devices in the near future (Swartz, 2000). In line with this trend, many sectors have witnessed the benefits of mobile technology that are enabled by wireless networks. In the finance sector, business models have been discussed for mobile brokerage services (Looney et al, 2004); in the banking industry, mobile payment has increasingly become a common practice (Herzberg, 2003); in the transportation business, future applications and research possibilities of mobile commerce inside vehicles has been discussed (Varshney, 2005); in the healthcare business, mobile computing has been foreseen as the next influential technology development (Turisco, 2000) and physicians' acceptance behavior of mobile devices has gained researchers' particular interests (Shengnan et al, 2006)

Despite the growing interests in mobile commerce and wireless network technology, recent empirical studies that have directly

Copyright (C) 2010 Wenshin Chen and David Bennett. This is an open access article distributed under the Creative Commons Attribution License unported 3.0, which permits unrestricted use, distribution, and reproduction in any medium, provided that original work is properly cited. Coontact author: Wenshin Chen. E-mail: wenshinchen@ hotmail.com 
examined mobile technology simply focused on specific contextual factors. Those contextual factors included identifying the paradoxical issues of mobile technology (Jarvenpaa and Lang, 2005), individual usage experiences in a particular industry (Cousins and Robey, 2005), the interaction with mobile technology in policing operations in UK (Sørensen and Pica, 2005), and mobile telephone usage in cars (Henfridsson and Lindgren, 2005). Little attention is paid in the literature to cultural changes that are enabled by mobile and wireless network technology.

The significance of understanding cultural changes in the context of wireless network technology is that culture shapes group identity and interaction (Turner, 1998) and often inserts profound influence on technology development (Tomlin, 1991) and/or business strategy (Sutherland and Morieux, 1988). Cultural changes that are facilitated by emerging technology would imply that an organization might require different technology management or business strategy for the next development or implementation of information technology. Logically, failing to articulate those emerging changes that are surfaced in different cultural elements would leave an organization with little vision and guidance for future IT management and business practice.

The purpose of this study is thus to examine how organizational culture is shaped by emerging wireless networks and mobile technology. Specific research questions are "in what elements do wireless network and mobile technology change an organization's culture?" and "how cultural changes enabled by emerging technology can help transform an organization?" Whereas most cultural studies in technology management investigate the effects of culture on technology implementation (Cabrera et al., 2001, Harper and Utley, 2001, Steensma et al, 2000), this study examines the reverse effects instead and helps understand technology effects on culture. Consequently, insights gained from the study could help IT and business managers to better strategize their future technology development in general and wireless network movement in particular.

\section{IT and Culture}

Sociologists define culture as the interactive pattern and collective behavior that are recognized and practiced by a group of actors (Turner, 1998). In society, culture simply structures social relations and reflects how societal members live their everyday life (Altman and Baruch, 1998). Such reflection is largely based on a set of shared values that distinguish members of one group from those of another (Hofstede, 1980/1981). These shared values help members in the same group address the primary concern of their social relation as to "who I am" and "how should I behave". In doing so, actors who shared the same cultural values could recognize one another and establish their social identity in a group (Thompson and Wildavsky, 1986). In an organization, these actors' collective behavior and social identity would form organizational culture as a whole and guide their work routine and communication patterns.

In the domain of information technology, culture studies have paid increasing attention to cultural impacts on business practice and technology development (Kass, 1991, Balsamo, 1996, Katz and Townsend, 2000). For instance, cultural norms in Europe are found to influence all aspects of information and communication technology (ICT) strategies including product development, sales strategy, sales cycle and product deployment (Tse et al., 2004); virtual teams' decision making is found to be significantly influenced by cultural diversity and its communication process is somehow hindered by it (Shachaf, 2008); organizational culture also plays a distinctive role in an organization's decision to adopt a 
high-technology product (Sharma, 1994); more specifically, people-oriented elements of organizational culture such as trust, team work, autonomy, flexibility, and information sharing, appear to have more positive influence on a successful IT implementation (Harper and Utley, 2001).

While these culture studies raise awareness of the significance of culture in relation to technology development and management, they tend to view organizational culture as a driving force or influential effects on the development or implementation process of information technology. In other words, the results about which these research primarily concern are technology acceptance, implementation and development. Organizational culture to them is one of the factors that might lead to different implementation results. Even a rare study that examines the interaction between information systems, most specifically ERP (enterprise resource planning), and organizational culture, concludes that it is an organization's cultural context that influenced whether a new system will be deployed (Kayas et al, 2008). As such, there appears a gap in the existing body of knowledge about organizational culture and information technology. More specifically, little could be concluded regarding how emerging ICT in general and wireless networks in particular shape or reshape collective behavior and shared values in a group, i.e. organizational culture.

Such inadequate understanding of how emerging technology shapes organizational culture is an unfortunate situation in the research community and business world because IT managers would not be able to strategize information technology to cultivate or reshape organizational culture that could encourage or facilitate future technology management and development in the organization. For example, information sharing, collaborative, flexible and autonomous work environments are some of cultural elements in organizations that could benefit technology deployment and development (Harper and Utley, 2001). If IT managers could utilize information technology to cultivate these types of organizational culture, organization members could then conduct their businesses more flexibly, share information more openly, communicate with one another more effectively, or create autonomous thinking and practice that goes beyond their ordinary routines. All of which could in turn help benefit an organization's future IT management tremendously.

\section{Research Methodology}

The methodology deployed here is based on a qualitative case study, which is considered appropriate for our research purpose because case study research methodology is the most widely adopted qualitative methodology in our research community (Orlikowski and Baroudi, 1991, Chen and Hirschheim, 2004), particularly when the purpose of research study focuses on in-depth analysis of research context (Yin, 1994). Two organizations investigated in the study are City Center Hospital (CCH) and Community Medical Center (CMC); both are in a metropolitan area located in southwestern USA. These hospitals provide contrasting cases not just because of their physical location and sizes but also because of their medical reputation and IT practice.

\section{Organizational context}

The first hospital, $\mathrm{CCH}^{1}$, is a renowned hospital regionally and nationally housing more than 4000 employees and almost 1000 beds. It is a frequent winner of "Most Wired Hospitals," an annual survey conducted by HHN (Hospitals and Health Networks) to identify hospitals that best utilize information technology to address five specific areas in the health care service provided. These five major areas include business processes, customer service, safety and quality, workforce, and public health

\footnotetext{
${ }^{1}$ All names in the study are pseudonyms.
} 
and safety (health.usnews.com). In addition, $\mathrm{CCH}$ is recognized several times as one of the "100 Best Companies to Work For," a famous survey conducted by Fortune to distinguish the best employers in the U.S. Several of its health care specialties have also help $\mathrm{CCH}$ to gain reputation as one of "America's Best Hospitals" by U.S. News \& World Report. CCH's large central IT department consists of approximately 160 IT staff in several functional units that serve more than thousands of computing and mobile devices, including physician and nursing applications.

The second hospital, CMC, in contrast, is often considered as a relatively smaller community hospital that serves certain suburban of the metropolitan area with approximately 150 beds housed. In the late 1990s, CMC was merged into one of the largest hospital chains in the U.S. through a greater acquisition between two for-profit hospital corporations. CMC's original IT department consisted of several staff members to serve its clinical application needs. In 2006, however, the corporation decided to outsource the IT department of each hospital in the region to its corporate outsourcing partner. The IT services thus has been centralized by the headquarters and supervised by one IT director who oversees several subsidized hospitals' IT functions in the metropolitan area.

\section{Data collection}

The data reported here were collected in three academic semesters during our non-teaching days at that time. Although other collection techniques such as documentation and participant observations were also conducted, most data were based on semi-structured interviews. More specifically, data analysis in the paper is derived from sixteen interviews conducted with twenty individuals (ten from each organization). We followed the same guidelines for all interviews. They were digitally recorded and the average recording time of each interview was 56 minutes. In the end, one hundred and ninety two pages of textual data were derived from the transcription and provided the basis of our data analysis.

\section{Wireless Backdrop}

As a renowned hospital in the region, $\mathrm{CCH}^{\prime} \mathrm{s}$ first movement toward wireless network was unsurprisingly launched rather early approximately in 1995 when no commercial wireless protocol was standardized. Although such an experiment demonstrated its health care system's pioneering enthusiasm to deliver more efficient and precise patient care, the implementation and utilization of network was relatively limited and virtually unknown to many staff members who were not directly involved. In many IT staff members' recollection, the first hospital wide wireless network was actually recorded and realized in 1998 when commercial wireless technology still evolved around a proprietary system using just 802.11 technology (instead of later more standardized $802.11 \mathrm{~b}$ protocol). The hospital's initiative was to enhance nursing staff's bedside charting effectiveness with the idea of "point of care system" through which nursing staff could simply barcode a patient's armband for information retrieval and reconfirmation provided via wireless network system. In addition, $\mathrm{CCH}$ recognized the electronic trend highly developed in the late 1990s and intended to transform from traditional paper chart system to 'paperless' system. As newer wireless protocols became more commercially available, CCH soon expanded and upgraded its network system and continued its pioneering bedside charting and patient care.

As a local community hospital and a relatively smaller division of a larger corporate healthcare system, CMC's wireless initiative came considerably later than the popular wireless trend in the industry. While the first access point was implemented in 
the ER (emergency room) approximately in 2002 , its existence was not commonly recalled let alone utilized by staff members interviewed. Four years later, with the larger corporate initiative of mobile registration for patient care, CMC finally came to witness its house wide wireless network and relevant technology. Compared to CCH's pioneering experiment in the late 1990s, CMC has been situated in its local community where the wave of wireless network and ICT development was not influential enough to sweep it until a few years later. Interestingly, CMC also experienced certain "leapfrog effect" where its wireless implementation simply leaped forward to newer wireless protocol and did not need to deal with the continuous upgrade and replacement of various wireless standards as $\mathrm{CCH}$ did. Its electronic medical record (EMR), an information system that computerizes medical records in digital format, was implemented to its full potential while the vast majority of American hospitals still relied on its traditional paper system and some only adopted EMR to its partial scale.

\section{Wireless Experiences at $\mathrm{CCH}$}

The implementation of wireless networks was first and foremost required to enable the corporate objective of moving toward electronic medical systems that fitted with the societal and health care trend. When $\mathrm{CCH}$ evaluated its $\mathrm{Y} 2 \mathrm{~K}$ problem, the assessment led to its realization that electronic systems and wireless infrastructure would be an inevitable trend for the health care business. The transformation of business operations and corporate movement was thus launched and the value of reducing manual labor for paper works was soon achieved. More specifically, CCH's wireless movement was in line with its business strategy to transform the organization into a paperless or paper light hospital
So our objective is always moving toward to the direction of eliminating papers... the whole objective was to migrate to at that point was called, paperless, but where to what we call now paper light... You go to insurance company, it is all... there is no paper, it is all electronic submission. We have certainly been more efficient, been able to do the volume that we are doing, not to generate all that paper work. [Jared, Chief Information Officer (CIO)]

Moreover, an increasing trend with the use of wireless networks and ICT emerged in that the perception of interaction and communication pattern has gradually changed. With all these ICTs embedded in the organization, CCH's members began to witness the extensive penetration of wireless networks not just in the business processes but also in cultural evolution which significantly changed members' communication patterns and expectation.

From my social perspective, from the communication perspective, having those types of technologies, to communicate and be interactive, is where the world is going to and it is bridging the geographical divides, you know, whereas if I need something from somewhere else I can get to it. I think its great; the world is evolving culturally and socially and I think that is a major benefit. It not only bridges the geographical side but the cultural side as well. [Adam, Project Manager]

Such cultural evolution, possibly unexpected, helped transform traditional business mentality where individuals tended to resist changes and focused on their own territories. As the wireless networks and ICTs freed the constraint of time and space and in turn collapsed the meaning of boundaries, individuals within the boundaries of institutions or facilities were exposed to constantly changing courses of action. Consequently, their collective behavior, which largely defined the notion of organizational culture, was inevitably 
renovated.

Most institutions whether they are health care or otherwise, I believe are naturally change resistant, they like to do what they are comfortable doing, to which is human nature, it is just the way it is, and people develop that silo mentality of "this is my world, this is what I focus on, I don't care what you are doing." $\mathrm{CCH}$ is the same thing. But when you start implementing computer systems and wireless technology and other things that are state of the art and are always changing and improving, I don't think you can help but make the culture of your facility or institution also change with that, becomes less afraid of changes, more willing to adopt it, embrace it, look forward to it. [Carl, Lead Analyst]

\section{Wireless Experiences at CMC}

As wireless networks and ICTs continued to be incorporated into the hospital's operations, a noticeable transformation of CMC was made to market itself as a more capable, full-scale facility. These emerging wireless technologies included "computer-on-wheels" (wireless diagnosis system), mobile language translation systems, and guest wireless networks. Ultimately, as the hospital's medical operations were transformed, a greater realization of a healthier community has subsequently emerged.

I think we are marketing that we are going to bring values to patients, that we are able to use some of our clinical technology to be able to diagnose... so the value for our community is we are gonna be able to help our patients diagnose, treat, prevent medical issues that we weren't able in the past, or weren't able to proactively. So I think that is gonna impact on our community, a healthier community. [Toby, Patient Care Director]

Finally, the newly launched guest wireless networks and relevant services enabled patients' or visitors' internet accessibility and allowed them to obtain critical administrative or medical information instantly. This new patient service did not just reduce medical processing time for patients but also more importantly expanded traditional medical service to different channel and renovated patients' and/or visitors' healthcare experience with CMC. The continuous transformation of CMC from a suburban community hospital to a complete facility has increasingly manifested itself.

If patients come in our hospitals right now, we have a waiting area in the lobby somewhere, the patient can sign on through their laptop, look at their schedule, change it or cancel their appointment to another date when it is gonna be less wait for them. Or when they have a test, and they want to know what the price is, or look at the cat scan, compare that to hospitals in the area, I think there are a lot information for them, and possibly entertainment; they could utilise their laptops, listening to music or watching movies, while they are waiting for their services or while they are in their beds in the hospital. [Toby, Patient Care Director]

However, such emerging transformation at CMC was an extensive learning process over the years. In a larger hospital such as $\mathrm{CCH}$, the capitalization of wireless networks and relevant technology was less problematic because there were plentiful IT resources and mostly prior experiences and expertise. At CMC, the IT resources and implementation experiences were less reachable so that its staff members often continued previous routines without acknowledging the existence, let alone the benefit, of newly deployed wireless networks and relevant technology. For instance, when CMC's medical records, traditionally maintained and controlled by the office of medical records, were made available electronically, nurses and staff members often made unnecessary requests to the office of medical records. More specifically, cultural change of collective behavior at $\mathrm{CMC}$ also reflected in its 
incremental organizational learning as indicated by Mary's message below.

Well, I think it's just simply because there wasn't much technology otherwise. This [electronic medical record] was the first; it was a big step. The nurses were used to using a different program than we had upstairs to access lab and radiology results and it was something they had always used... They were so in the habit of calling down here, "I need the old information to clear a patient's chart." "Well, did you look in the record?" "Well, no." "Ok, well that should be your first place to look"... It was hard for them to realise they didn't have to pick up the phone and rely on someone else. They could just go to the record and pull it up themselves. [Mary, Director of Medical Records]

In the ER, the utilization of electronic medical systems did not improve but impede productivity at first. ER physicians whose income were also a formula of the number of patients treated were accustomed to paper charts and naturally reluctant to learn the new system in the beginning; their reluctance or fear of learning the new system was understandable because it on the surface required substantial effort and very importantly denoted the immediate reduction of patients treated and income reduced. Nevertheless, Dr. Dale, ER director, anticipated its continuous acceptance once the system was completely infused and normalized within the hospital. As such, the emergence of wireless networks and relevant technology also created a critical learning opportunity for doctors at CMC to acknowledge and appreciate the state of the art technology that was increasingly creating a new norm for CMC's cultural transformation.
Actually, in the technology, we have less success because with the technology we slowed down the productivity because you have to learn the new system. You spend so much with computers and you spend less time with patients. And in fact, there are lots of doctors who are afraid of the system, they do, they are afraid of it. They say, 'man, I don't want to spend time learning this thing; I don't want to; I rather spend time with patients than sit down and spend 5 or 10 minutes to do the charting in a computer.'... Right now, it is a big deal for us now because it is still so new. I am sure three, four years from now, everybody is using it and we all forget about it... But once it becomes universal and everybody is using and we just forget about the hassle we have to go through. And it will become the new norm. [Dr. Dale, ER Director]

\section{Case Discussions}

Our first research question asks, "In what elements do wireless network and mobile technology change an organization's culture." Findings from these two hospitals demonstrated that two similar cultural elements were being reshaped by wireless network and mobile technology. These changes were about corporate image and organizational learning while the former related to how organization members identify themselves and the latter reflected in its collective behavior.

Changes in corporate image

At $\mathrm{CCH}$, wireless networks and mobile technology was a part of strategic plan that transformed the organization into a paperless or paper light hospital. As illustrated in Jared's message, they also helped with $\mathrm{CCH}$ to accomplish electronic medical records that were highly discussed and sanctioned due to HIPAA (Health Insurance Portability and Accountability Act) which was not the focus of our study. Evidently, without wireless networks and mobile technology, such cultural changes in corporate images (i.e. collective identity) 
would not be possible. In contrast, CMC's corporate image was transformed or more precisely elevated via wireless networks and mobile technology mostly because these cutting edge technologies allowed CMC to compete with larger hospitals such as $\mathrm{CCH}$ at a similar level and subsequently rebuilt its community image. Previously, CMC was mostly considered as a suburban hospital that merely served a small local community. As illustrated in Toby's message, a more technologically capable image and thus a healthier community hospital was renovated by these emerging technologies implemented at CMC.

\section{Changes in organizational learning}

Both hospitals also demonstrated similar cultural changes in organizational learning (i.e. collective behavior) that was not discussed in the literature. At $\mathrm{CCH}$, as explained in Carl's message, most people tended to resist change. However, with wireless networks and mobile technology, $\mathrm{CCH}$ continued its cutting edge practice and subsequently shaped an innovative culture that encouraged its members to learn and embrace changes. Although wireless networks and mobile technology were not directly responsible for cultivating such innovative culture, they reinforced CCH's strategic practice that wan them many awards for emphasizing continuous learning and innovation. At $\mathrm{CMC}$, cultural changes in organizational learning were even more evident. As a community hospital, all these emerging technologies were new experiences to its members. As illustrated in Mary's message, nurses really needed to change their routine and traditional practice step by step to get used to the convenience brought by these emerging technologies. Similarly, as indicated by Dr Dale's message, the learning experiences for doctors appeared dramatic before utilization of wireless networks and mobile technology became a new norm.

Changes in communication

At $\mathrm{CCH}$, certain cultural change in communication pattern was also evident. Wireless networks and mobile technology allowed ubiquitous communication in organization members' fingertips. It did not just improve communication effectiveness but also change collective social and cultural expectation as to how communication should be done. As illustrated by Adam's message, members now knew they can send and receive information instantly from anywhere. Their communication pattern has become more simultaneous and interactive that was not possible without these emerging technologies. At CMC, interviewees did not specify such effects. It might be due to their slower learning process because members were not used to rapid technological changes as indicated in Mary's and Dr Dale's messages.

Changes in service renovation

At CMC, a specific kind of culture changes was further indicated in service renovation. Patients could now interact with the hospital's registration system or even entertain themselves in the lobby area. This emerging practice was completely enabled by wireless networks and mobile technology. It provided different types of services to patients or community members that were not previously possible. For a smaller community hospital, newly implemented wireless networks and mobile technology presented a new platform that allowed the hospital to renovate its services. At $\mathrm{CCH}$, such effects were less evident (or at least not emphasized by interviewees) probably because $\mathrm{CCH}$ has been innovative over the years. CCH's organization members were more used to continuous technology development and thus did not pay particular attention to the emerging effects of wireless networks and mobile technology on service renovation.

\section{Changes \& corporate transformation}

Our second research question inquires, "How cultural changes enabled by emerging technology can help transform an organization?" The discussion of CCH's and 
CMC's wireless network experiences has demonstrated that cultural changes enabled by wireless networks and mobile technology could transform an organization's image that helped the organization to reposition itself in the competitive marketplace. At $\mathrm{CCH}$, it helped transform the hospital into a paper light center that emphasizes cutting edge strategic practice. At CMC, it enabled the hospital to rebuild its image in the community and to elevate its competitiveness in the field.

In addition, wireless networks and mobile technology helped transform organization members' mentality. At $\mathrm{CCH}$, members became less change resistant and in turn more capable of learning and embracing new changes. In the long run, a more innovative culture is guaranteed which could in turn help future technology management or organizational changes. At $\mathrm{CMC}$, the transformation in organizational members' everyday practice was even more drastic. Although it took longer learning process, members were increasingly forced to deal with or better utilize these emerging technologies. Their work routine has profoundly altered and mentality increasingly changed. It is thus expected that a more technologically capable culture is gradually established at CMC as well.

\section{Implications}

To practitioners, CCH's and CMC's wireless network experiences demonstrated a clear linkage between emerging technologies and cultural changes. While previous literature often focused on how organizational culture influences technology development or implementation, this study shows that emerging technologies in general and wireless networks in particular could also influence organizational culture. These findings would then suggest that IT or business managers need to strategize the organization's IT practice well. For an innovative, reputable organization such as $\mathrm{CCH}$, the implementation or development of emerging technologies needs to be in line with the existing business culture so that cultural changes enabled by technologies implemented could continue to reinforce its innovative image. For a smaller and less recognized organization such as CMC, cultural changes enabled by emerging technologies could be revolutionary and thus need to be taken into careful consideration. A more incremental, systematic implementation process is recommended so that sufficient learning is introduced to organization members before drastic cultural changes that could create unexpected results occur.

For researchers, further questions could be derived from this study's findings. A logical one would be "how do those cultural changes enabled by wireless networks sustain?" This research question might be of future studies' particular interest because it offers opportunity to understand the long term effect of technology culture. As indicated by the existing literature, organizational culture often influences technology development. It could then be theorized that these cultural changes enabled by wireless networks and mobile technology would also influence future technology management. The aforementioned research question could then provide an empirical test to such a proposition. Another possible research question is "in what elements do other emerging technologies (such as ERP or RFID) change organizational culture?" This question could be particularly insightful because it expands empirical test from this study to other technology area so that a broader understanding of how emerging technology in general reshape organizational culture could be reached. Since the study only focuses on the healthcare sector, future studies in other industries might also provide interest contrast or confirmation to our findings. 


\section{Concluding Remarks}

This study sought to understand cultural changes enabled by wireless networks and mobile technology, a topic that was not commonly discussed in the existing literature. The research findings and discussion have shown that emerging technologies in general and wireless networks in particular could indeed reshape certain aspects of cultural elements, most specifically in transforming corporate image, learning mentality, communication pattern, and service practice. Although there were only two organizations in the healthcare sector examined, this case study provided an exploratory possibility for future research endeavor to continue building greater understanding of the relationship between emerging ICTs and organizational culture. Future research efforts to broaden and deepen the insights provided by this study are thus highly encouraged.

\section{References}

Altman, Y. \& Baruch, Y. (1998) Cultural Theory and Organizations: Analytical Method and Cases. Organization Studies, 19, 769-785.

Balsamo, A. (1996) Myths of Information: The Cultural Impact of New Information Technologies. Technology Analysis \& Strategic Management, 8, 341.

Cabrera, A., Cabrera, E. F. \& Barajas, S. (2001) The Key Role of Organizational Culture in a Multi-System View of Technology-Driven Change. International Journal of Information Management, 21, 245-261.

Chen, W. \& Hirschheim, R. (2004) A Paradigmatic and Methodological Examination of Information Systems Research from 1991 to 2001. Information Systems Journal, 14, 197-235.

Cousins, K. C. \& Robey, D. (2005) Human Agency in a Wireless World: Patterns of Technology Use in Nomadic Computing
Environments. Information and organization, 15, 151-180.

Harper, G. R. \& Utley, D. R. (2001) Organizational Culture and Successful Information Technology Implementation. Engineering Management Journal, 13, 11.

Henfridsson, O. \& Lindgren, R. (2005) Multi-Contextuality in Ubiquitous Computing: Investigating the Case through Action Research. Information and organization, 15, 95-124.

Herzberg, A. (2003) Payments and Banking with Mobile Personal Devices. Communications of the ACM, 46, 53-58.

Hofstede, G. (1980/1981) Culture and Organizations. International Studies of Management \& Organization, 10, 15-41.

Jarvenpaa, S. L. \& Lang, K. R. (2005) Managing the Paradoxes of Mobile Technology. Information Systems Management, 22, 7-23.

Kass, T. (1991) Culture and Technology. Technology Analysis \& Strategic Management, 3, 285.

Katz, J. P. \& Townsend, J. B. (2000) The Role of Information Technology in the 'Fit' between Culture, Business Strategy And. Journal of Global Information Management, $8,24$.

Kayas, O. G., Mclean, R., Hines, T. \& Wright, G. H. (2008) The Panoptic Gaze: Analysing the Interaction between Enterprise Resource Planning Technology and Organisational Culture. International Journal of Information Management, 28, 446-452.

Looney, C. A., Jessup, L. M. \& Valacich, J. S. (2004) Emerging Business Models for Mobile Brokerage Services. Communications of the ACM, 47, 71-77. 
Orlikowski, W. \& Baroudi, J. J. (1991) Studying Information Technology in Organizations: Research Approaches and Assumptions. Information Systems Research, 2, 1-28.

Shachaf, P. (2008) Cultural Diversity and Information and Communication Technology Impacts on Global Virtual Teams: An Exploratory Study. Information \& Management, 45, 131-142.

Sharma, A. (1994) Organizational Culture and Adoption of High-Technology Products. Journal of Marketing Management, 10, 513-526.

Shengnan, H., Mustonen, P., Seppanen, M. \& Kallio, M. (2006) Physicians' Acceptance of Mobile Communication Technology: An Exploratory Study. International Journal of Mobile Communications, 4, 1-1.

Sørensen, C. \& Pica, D. (2005) Tales from the Police: Rhythms of Interaction with Mobile Technologies. Information and organization, 15, 125-149.

Steensma, H. K., Marino, L., Weaver, K. M. \& Dickson, P. H. (2000) The Influence of National Culture on the Formation of Technology Alliances by Entrepreneurial Firms. Academy of Management Journal, 43, 951-973.

Sutherland, E. \& Morieux, Y. (1988) Effectiveness and Competition--Linking Business Strategy, Organizational Culture and the Use of Information Technology. Journal of Information Technology (Routledge, Ltd.), 3, 43.

Swartz, N. (2000) M-Commerce Cometh. Wireless Review.

Thompson, M. \& Wildavsky, A. (1986) A Cultural Theory of Information Bias in Organizations. Journal of Management Studies, 23, 273-286.
Tomlin, R. (1991) Developing a Management Culture in Which Information Technology Will Flourish: How the Uk Can Benefit. Journal of Information Technology, 6, 45-55.

Tse, T., Tiong, J. \& Kangaslahti, V. (2004) The Effect of Cultural Norms on the Uptake of Information and Communication Technologies in Europe: A Conceptual Analysis. International Journal of Management, 21, 382-392.

Turisco, F. (2000) Mobile Computing Is Next Technology Frontier for Healthcare Providers. Healthcare Financial Management.

Turner, J. H. (1998) The Structure of Sociological Theory, Belmont, CA, Wadsworth Publishing Company.

Varshney, U. (2005) Vehicular Mobile Commerce: Applications, Challenges, and Research Problems. Communications of AIS, 2005, 329-339.

Yin, R. K. (1994) Case Study Research: Design and Methods, Thousand Oaks, CA, SAGE Publications. 